\title{
A Research on a Genetic Algorithm for Hybrid Production Style
}

\author{
Zijian Zhang, Lili Jiang and Qiang Zhang \\ School of Mechanical and Electronic Engineering, Guangdong University of Technology, \\ Guangzhou510000, Guangdong, P.R. China nanzhui1981@163.com
}

\begin{abstract}
According to the coexistence of two production style: Single Small Serial Production and Batch Production in the current Enterprise, this article analyzed the scheduling problems of this production model and studied the working flow of this production scheduling problem. Using Genetic Algorithm for the Scheduling Hybrid Production, a new system for solving the problems of Scheduling Hybrid Production is set up, combined with some examples in the process of actual manufacturing. It has been proved that this system could solve some problems of Hybrid Production Scheduling.
\end{abstract}

Keywords: Hybrid production, Genetic algorithm, System of production scheduling

\section{INTRODUCTION}

Based on the aim and some restrictions of manufacture process, the goal of Jobscheduling is to ascertain machining routes, time, machine tools and operations for each work piece, it has a close relationship with the accomplishment and productivity of each product, So Job-scheduling is always an active research area of manufacturing. Although lots of achievements on this subject have been developed, quite a number of those achievements are based on the classical Job-scheduling problems, which assume (1)every workpiece has more than one working procedures, each of the working procedure must be operated on an appointed machine tool. (2) every kind of work piece is treated as a whole accessory for transportation, machining and scheduling, regardless the amount (batch) of it. Obvious, those kinds of achievements can not meet with the characteristics and requirements of the manufacture system and Job-scheduling in the future. To be more concretely, nowadays there are so many enterprises that have a Hybrid production predicament such as coexistence of Single Small Serial Production and Batch Production. The productions' diversification and uncertainty contribute a great number of managing problems and lead to more complicated scheduling process. Therefore, how to resolve those Hybrid Production Scheduling problems is of important practical and immediate significance.

According to the coexistence of Single Small Serial Production and Batch Production in the current Enterprise, and to the popularization of Flexible Manufacturing System (FMS), a working procedure can be accomplished on more than one machine tool. In order to improve productivity and efficiency, this paper

Please use the following format when ciling this chapter:

Zhang, Z., Jiang, L., Zhang, Q., 2007, in IFIP International Federation for Information Processing, Volume 255, Research and Practical Issues of Enterprise Information Systems II Volume 2, eds. L. Xu, Tjoa A., Chaudhry S. (Boston: Springer), pp. 1413-1417. 
introduces a new idea on the problem of scheduling flow shops with lot streaming, namely interleaving of sublots from different lots within a job sequence and machining on different machine tool. The overall situation is optimized via Genetic Algorithm (GA).

\section{MODEL FORMULATION}

The scheduling problems belong to the discrete production scheduling problems, which needs to find a way to solve the minimum cost problem during dynamic production. The objective function of this model is to minimize the weighted summation of manufacture time, manufacture cost and stock cost of one project. In addition, because of the characteristics of due date constraint in various batch productions, this paper proposed to adopt Regulation of Due Date Loose Variables to schedule workpieces in each sublot, while simultaneously consider production capacity restriction, procedure restriction and single machine capacity restriction. Finally we could accomplish the scheduling system of Hybrid Production.

Based on the practice of scheduling Hybrid Production, we describe the problem as follows:

M: index set of machines.

$\mathrm{N}$ : index category of work pieces. It is assumed (without loss of generality) that $\mathrm{N}$ categories of work pieces are processed initially on machine M1, followed by machine M2, etc with fixed working procedures. Production assignment is divided up to $T$ sublots according to Master Production Scheduling, and the amount of each workpiece in every sublot is ascertained.

According to the cycle of materiel deliver, the amount of materiel deliver and the capacity of stock, we must ascertain production batch of each work piece in one project at first, and then find out production lot of each work piece in individual sublots on the basis of scheduling restraints.

Here the restraints we considered are:

1 Every working procedure of any work piece can only start after the previous working procedure is completed;

2 Once one working procedure was started, it can not be halted;

3 There can only be one work piece on one machine;

4 The start time of every working procedure of any work piece must be a nonnegative number;

5 One production assignment can only start after the other one was completed on the same machine;

Assume an ideal state as follows:

1 The amount of every sublot must meet with the needs of one whole project;

2 Machining process of any workpiece must be continuous.

Formulate the model of Hybrid Production Style as follows:

$$
I_{i, t-1}+X_{i t}-d_{i t}=I_{i t}
$$

Stock balances equation 


$$
\sum_{i=1}^{N} a_{i k} X_{i t} \leq S_{k t}
$$

Restriction of production capacity

$$
I_{i 0}=I_{i T}=0
$$

Stock is 0 at the start and end time of one project

$$
\begin{gathered}
t_{i k t}-t_{i k t^{\prime}}-p_{i k t^{\prime}} X_{i t^{\prime}} \geq 0 \\
\forall\left(o_{i k^{\prime} t}, o_{i k t}\right) \in G A
\end{gathered}
$$

Restriction of working procedure

- $\quad t_{i k t}-t_{i^{\prime} k t^{\prime}}-p_{i^{\prime} k t^{\prime}} X_{i^{\prime} t^{\prime}} \geq 0$

$$
\forall\left(o_{i^{\prime} k t^{\prime}}, o_{i k t}\right) \in G E_{k}
$$

Order restriction of work piece

$$
\text { - } \quad X_{i t}, I_{i t} \geq 0
$$

$$
\forall i \in N, \forall t \in T
$$

Decision-making variables are positive number

$$
\begin{aligned}
& \Gamma_{1}=\sum_{i=1}^{N} \sum_{i=1}^{T} p_{i t} X_{i t} \\
& \Gamma_{2}=\sum_{i=1}^{N} \sum_{t=1}^{T} h_{i} I_{i t} \\
& \Gamma_{3}=\sum_{i=1}^{N} \sum_{t=1}^{T}\left(t_{i k t}+b_{i k} X_{i t}\right) \\
& H=Q-\Gamma_{1}-\Gamma_{2}-\Gamma_{3}
\end{aligned}
$$

Where

$\mathrm{p}_{\mathrm{it}}$ : Unit production cost of work piece $\mathrm{i}$ in sublot $\mathrm{t}$;

$X_{i t}$ : number of work piece $i$ in sublot $t$;

$\mathrm{I}_{\mathrm{i}}$ : stocks of work piece $\mathrm{i}$ in sublot $\mathrm{t}$;

$d_{i t}$ : demand of work piece $i$ in sublot $t$;

$\mathrm{S}_{\mathrm{kt}}$ : overall working time of machine $\mathrm{k}$ in sublot $\mathrm{t}$;

$\mathrm{O}_{\mathrm{ikk}}$ : operation of $\mathrm{J}_{\mathrm{it}}$ on machine $\mathrm{k}$;

$p_{i k t}$ : machining time of operation $o_{i k t}$ of work piece $i$; 
$b_{i k}$ : machining time of work piece $i$ on machine $k$;

GA: aggregate of all the working procedure;

$\mathrm{GE}_{\mathrm{k}}$ : aggregate of all the working procedure on machine $\mathrm{k}$.

$\Gamma_{1}$ : production cost of one project;

$\Gamma_{2}:$ stock cost of one project;

$\Gamma_{3}$ : completion time of one project;

Q: very big positive number;

$\mathrm{H}$ : objective function of the model,

Aim of Objective function of this model is to minimize the weighted summation of manufacture time, manufacture cost and stock cost of one project.

\section{SOLUTION OF SCHEDULING}

The approach developed in this paper is based on GA, which is more suitable and relatively easy to deal with the issue of the number of sublots. GA is used to determine the number of sublots and the associated sequencing, while a mixed-integer programming model (MIP) is used to determine the size of the sublots for the $n$-job, $m$-machine flow shop problem with the objective of minimizing the producing span. Detailed arithmetic is generalized as follows:

Step 1: Initialize parameters of all the genes, and then generate an initial solution by heuristic arithmetic.

Step2: Get a new solution by linear programming arithmetic, if the solution can not fit the objective function, turn to step3, otherwise turn to arithmetic 2 , ascertain production sequence of every work piece in each sublot, and then calculate objective function $\mathrm{H}$, set $\mathrm{i}=1$.

Step3: Evaluate the scheduling result till we get the best chromosome and evaluation, let $i=i+1$. If it can not be obtained, turn to Step4.

Step4: Start genetic operation, including select operation: select as many chromosomes as pop-size from the aggregate of chromosomes which is enlarged after crossover and mutation operation. Apply a crossover method to create two offspring.

Step5: Terminate arithmetic until termination criteria is met.

When determining the sequence of workpieces in each sublot, we have to resolve the problems of Hybrid Production, namely the coexistence of two production styles: Single Small Serial Production and Batch Production. The model above has included manufacture time, cost and stock cost as its objective function. However, deadline is a most important restriction on various batch productions. So this paper proposed to adopt Regulation of Due Date Loose Variables to scheduling workpieces in each sublot. The detailed arithmetic is particularized as follows

Step1: Calculate Due Date Loose Variables of each workpiece in every sublot, slack $_{\mathrm{i}}=\mathrm{d}_{\mathrm{i}}-\mathrm{ST}-\sum_{j=1}^{n} p_{i j}$, and get a work piece sequence based on the magnitude of Due Date Loose Variables.

Step2: Arrange suitable machine for work piece $\mathrm{k}$ in the sequence, When starting to arrange a working procedure of every work piece, we choose a machine which can 
make the working procedure start as early as possible, and ascertain its starting and finishing time. Another workpiece can be started to arrange if only the arrangement of the previous one is done. After one workpiece is completed we must confirm whether the time required oversteps the latest time determined by its Due Date Loose Variables and calculate the objective function to get the optimal solution.

Step3: If $\mathrm{k}=\mathrm{n}$, then end compositor, if not turn to step2, and let $\mathrm{k}=\mathrm{k}+1$.

\section{CONCLUSIONS}

This paper introduces the idea of interleaving sublots from different lots in the face of major sublots minor setups to the multi-family flowshop scheduling problem. The problem is approached by a hybrid algorithm in which a GA is used to determine the number of sublots and the size of sublots. The GA also provides strong indications that the extremely difficult (sublots usually ignored) issue of the number of sublots is addressed effectively.

This module is accomplished on the basis of the quondam scheduling system developed by our team, with programming tools Delphi and SQLServer2000. At first we design an interface between this module and quondam system, import database files of quondam system, and then use model and arithmetic above, the program would create scheduling plan automatically. The planner can also modulate the sizes of sublots and start time of every working procedure manually. At last the program would build all kinds of production BOMs.

\section{ACKNOWLEDGEMENTS}

The research in this paper is supported by the scheming item of science and technology by Guangdong province (2004B50101004, 2005B50101011)

\section{REFERENCES}

1. R. Xiong, H. Chen, and B. Hu. An integration model for production planning and job scheduling and its Lagrangian relaxation-lased solution approach, Journal of Xidian University. Volume 23, Number 4, pp.510-516, (1996).

2. J.B. Lasserre, An integrated for job-shop planning and scheduling, Management Science. Volume 38, Number 8, pp.1201-1211, (1992).

3. H. Li, W. Peng, and H. Shi. Optimization model of production scheduling on the assemble shop floor, Machinery Design \& Manufacture. Volume 94, Number 2, pp.10013997, (2006).

4. V. Lo and J. Mache, Job Scheduling for Prime Time vs. Non-Prime Time, in Proc. of the IEEE international Conference on Cluster Computing (2002), pp.488-493.

5. X. Wang and L. Cao, Genetic algorithm-theory, application and software develop (Xi'an Jiaotong University press: $\mathrm{Xi}$ 'an, 2002).

6. W. Shang and $Y$. Fan, Integrated optimization modeling of production planning \& scheduling for batch production, Computer Integrated Mamufacturing Systems. Volume 12, Number 1663, pp.1006-5911, (2005). 